\title{
Termination of Epileptic Afterdischarge in the Hippocampus
}

\author{
Anatol Bragin, Markku Penttonen, and György Buzsáki \\ Center for Molecular and Behavioral Neuroscience, Rutgers, The State University of New Jersey, Newark, \\ New Jersey 07102
}

\begin{abstract}
The mechanism of afterdischarge termination in the various hippocampal regions was examined in the rat. Stimulation of the perforant path or the commissural system was used to elicit afterdischarges. Combination of multiple site recordings with silicon probes, current source density analysis, and unit recordings in the awake animal allowed for a high spatial resolution of the field events. Interpretation of the field observations was aided by intracellular recordings from anesthetized rats. Irrespective of the evoking conditions, afterdischarges always terminated first in the CA1 region. Termination of the afterdischarge was heralded by a large DC shift initiated in dendritic layers associated with a low amplitude "afterdischarge termination oscillation" (ATO) at 40 to $80 \mathrm{~Hz}$ in the cell body layer. ATOs were also observed in the CA3 region and the dentate gyrus. The DC shift spread at the same velocity $(0.1-0.2 \mathrm{~mm} /$
\end{abstract}

sec) in all directions and could cross the hippocampal fissure. All but 1 of the 25 putative interneurons in the CA1 and dentate regions ceased to fire before the onset of ATO. Intracellularly, ATO and the emerging DC potential were associated with fast depolarizing potentials and firing of pyramidal cells and depolarization block of spike initiation, respectively. Both field ATO and the intracellular depolarization shift were replicated by focal microinjection of potassium. We hypothesize that $\left[\mathrm{K}^{+}\right]_{\text {o }}$ lost by the intensely discharging neurons during the afterdischarge triggers propagating waves of depolarization in the astrocytic network. In turn, astrocytes release potassium, which induces a depolarization block of spike generation in neurons, resulting in "postictal depression" of the EEG.

Key words: epilepsy; spreading depression; oscillation; potassium; interneurons; ephaptic effects; glia
The most common form of seizures, complex partial epilepsy, arises in the hippocampal region (cf. Engel, 1989; McNamara, 1994). The seizures are often followed by depressed electrical activity, termed "postictal silence" (Engel, 1989). Numerous in vivo and in vitro models of epilepsy have investigated the emergence, maintenance, and spread of seizures. In contrast, relatively few studies have specifically addressed the issue of seizure termination (Liberson and Cadilhac, 1953; Penfield and Jasper, 1954; Gloor et al., 1961; Sypert and Ward, 1971; Leao, 1972; Heinemann et al., 1977; Haglund and Schwartzkroin, 1984; Somjen et al., 1985; Leung, 1987). The issue is important because understanding factors critically involved in ending an ongoing seizure may lead to a more effective treatment of epileptic patients.

The goal of the present investigation was to reveal the contribution of the various factors responsible for the termination of stimulation-induced afterdischarges in the intact brain. The laminar neuronal organization of the hippocampus (Amaral and Witter, 1989) makes this structure particularly relevant to investigate population synchrony and flow of extracellular currents. Nevertheless, in contrast to relatively stationary signals, such as

Received Nov. 4, 1996; revised Dec. 20, 1996; accepted Jan. 10, 1997.

This work was supported by National Institute of Neurological Diseases and Stroke Grants NS34994 and 1P41RR09754, Human Frontier Science Foundation, the Whitehall Foundation, and the Finnish Academy of Sciences (M.P.). We thank K. Wise and J. Hetke for manufacturing silicon probes; J. J. Chrobak, J. Csicsvari, S. L.-W. Leung, M. Page, G. G. Somjen, and R. D. Traub for their comments on an earlier version of this manuscript; and D. J. Dingledine, N. A. Lambert, P. A Schwartzkoin, and W. Wilson for advice.

Correspondence should be addressed to Dr. György Buzsáki, Center for Molecular and Behavioral Neuroscience, Rutgers University, 197 University Avenue, Newark, NJ 07102.

Dr. Bragin's permanent address: Institute of Theoretical and Experimental Biophysics, Puschino, Russia.

Dr. Penttonen's present address: A. I. Virtanen Institute, University of Kuopio, FIN-70211 Kuopio, Finland.

Copyright (C) 1997 Society for Neuroscience $0270-6474 / 97 / 172567-13 \$ 05.00 / 0$ evoked potentials and behavior-dependent oscillatory patterns, studying the laminar distribution of epileptic activity is difficult given the nonstationary nature of seizures and the time required to obtain samples repeatedly from different sites during successive afterdischarges (Wadman et al., 1992). This is especially true for slow currents generated by the glial network (cf. Heinemann et al., 1995). Multiple site recordings with equally spaced electrodes (Bragin et al., 1995; Ylinen et al., 1995) may alleviate this difficulty. In the studies reported below, we used high-resolution multiple site silicon probes for the continuous analysis of current source density and single unit activity during afterdischarges in the awake rat. Interpretation of the extracellular field and unit observations were further aided by intracellular recordings in the anesthetized animal. Seizures were elicited by stimulation of either the perforant path or the associational/commissural system because these protocols have most often been used in intact animals (Sloviter 1983; Leung 1987; Lothman and Williamson, 1993; Mody 1993), and because we wanted to investigate whether termination of afterdischarges depends on the initiation site.

\section{MATERIALS AND METHODS}

Surgery. Twenty-seven male and female Sprague Dawley rats (300-450 gm) were used in this study. The rats were anesthetized with a $4 \mathrm{ml} / \mathrm{kg}$ mixture of $25 \mathrm{mg} / \mathrm{ml}$ ketamine, $1.3 \mathrm{mg} / \mathrm{ml}$ xylazine, and $0.25 \mathrm{mg} / \mathrm{ml}$ acepromazine. Pairs of stainless steel wires $(100 \mu \mathrm{m}$ in diameter $)$ with 0.5 $\mathrm{mm}$ vertical tip separation were placed in the angular bundle unilaterally (right side) or bilaterally to stimulate the medial perforant path afferents to the hippocampus [anterior $=-7.0 \mathrm{~mm}$ from bregma, lateral $=3.5 \mathrm{~mm}$ from midline, and ventral $=-3.0 \mathrm{~mm}$. Another electrode pair was placed into the ventral hippocampal commissure (anterior $=-0.8$, lateral $=0.5$, ventral $=-4.2$ ) to stimulate the commissural afferents to the CA1-3 regions and the dentate gyrus.

Two different recording electrodes were used: stationary or movable wire electrodes and multisite recording silicon probes. Wire electrodes (two to four $60 \mu \mathrm{m}$ tungsten wires) were implanted in the strata pyrami- 
dale and radiatum of CA1, the molecular layer, and hilus of the dentate gyrus (anterior $=-3.0$, lateral $=2.6$, ventral $=-2.1$ to -3.1 ) and the CA3 pyramidal layer $($ anterior $=-3.0$, lateral $=3.2$, ventral $=-3.5$ ). For simultaneous recording of field potentials and unit activity in different hippocampal regions and layers, silicon probes micromachined with thinfilm technology were used (Bragin et al., 1995). In the 24-site probe, each of the 6 shanks had 4 recording sites $\left(9 \times 9 \mu \mathrm{m}^{2}\right.$ platinum-plated pads $)$ that were spaced $25 \mu \mathrm{m}$ apart. The shanks were $300 \mu \mathrm{m}$ apart. The thickness of the silicon shank was $15 \mu \mathrm{m}$ throughout. In the 16 -site single shank probe, the recording sites were $100 \mu \mathrm{m}$ from each other in the vertical plane $(80 \mu \mathrm{m}$ wide at the base, narrowing to $15 \mu \mathrm{m}$ at the tip). The recording sites were platinum-plated. A $3 \times 1 \mathrm{~mm}$ slot was drilled into the skull above the dorsal hippocampus, parallel to the long axis of the structure, through which the recording electrodes were inserted after cutting the dura mater. The silicon probes were inserted into the neocortex or corpus callosum during surgery. After recovery, the tips were lowered gradually into the hippocampus with the aid of a microdrive (Bragin et al., 1995). During the experiment, evoked field potentials helped guide the positioning of the microelectrodes. Two stainless steel watch screws driven into the bone above the cerebellum served as indifferent and ground electrodes.

Recording and stimulation. Six 4-channel MOSFET input operational amplifiers, mounted in the female connector, served to eliminate cable movement artifacts (Buzsáki et al., 1989a). Physiological data were recorded either wide-band $(1 \mathrm{~Hz}$ to $5 \mathrm{kHz}$ for units and field) or with an ultra slow time constant $(0.03$ or $0.1 \mathrm{~Hz})$ and sampled at $10 \mathrm{kHz}$ or 100 $\mathrm{Hz} /$ channel, respectively, with 12 -bit precision. The data were stored on optical disks. All analyses were carried out off-line on a 486/66 MHz PC and/or IBM RS 6000 computer. Afterdischarges were induced by a single $1 \mathrm{sec}, 200 \mathrm{~Hz}(0.1 \mathrm{msec})$ pulse train delivered to the perforant path (PP) or the commissural path (COM). The stimuli were supramaximal for evoking population spikes in the dentate gyrus (PP) or CA1 pyramidal layer (COM). If the train failed to induce an afterdischarge $(<5 \%$ of cases), the stimulus intensity or pulse duration was increased and tetanic stimulation was repeated after a rest period of at least $30 \mathrm{~min}$. The duration of the primary afterdischarge in each region was measured from the onset of large amplitude rhythmic waves with or without population spikes to the "isoelectric" silent period. The propagation velocity of the slow waves was determined from the latency of the negative peaks of the slow events and the distance of the recording sites. Nineteen of the animals also served as subjects in a previous experiment to study the emergence and maintenance of afterdischarges in the hippocampalentorhinal system (Bragin et al., 1996).

Current source density (CSD) analysis. Complete accounts of the theoretical basis of CSD analysis have been presented earlier (Freeman and Nicholson, 1975; Mitzdorf 1985). CSDs were calculated in one direction (depth), assuming that currents in the septotemporal and subiculofimbrial directions were negligible (Leung, 1979). Although some resistivity differences are present in the different hippocampal layers, in practice these are not large enough to significantly modify the spatial distribution of sinks and sources (Holsheimer, 1987). The CSD results are presented as the unscaled second derivative of potential as a function of depth, proportional to the actual current densities (Bragin et al., 1995; Ylinen et al., 1995). The exact anatomical layers corresponding to the vertical scale of the CSD maps were reconstructed with the aid of the histologically identified recording tracks and evoked potentials. Current sinks and sources associated with the activation of the PP and COM afferents provided precise landmarks for the identification of the recording sites. Unitary activity in the CA1 pyramidal layer provided an additional marker for the depth of the electrodes.

Histological procedures. After completion of the experiments, the rats were deeply anesthetized and perfused through the heart first with cacodylate-buffered saline $(\mathrm{pH} 7.5)$, followed by a cacodylate-buffered fixative containing $4 \%$ paraformaldehyde and $5.9 \%$ calcium chloride $(\mathrm{pH}$ 7.5). Brains were left in situ for $24 \mathrm{hr}$, removed, and then postfixed in the same solution for 1 week. The brains were sectioned with the probes left in the brain on a vibratome at $100 \mu \mathrm{m}$ in the coronal plane. The sections were stained with the Nissl method.

Intracellular methods. Seventeen Sprague Dawley (250-350 gm) rats were anesthetized with urethane $(1.3-1.5 \mathrm{gm} / \mathrm{kg})$ and placed in a stereotaxic apparatus. The body temperature of the rat was kept constant by a small animal thermoregulation device. The scalp was removed, and a small bone window $(2.0 \mathrm{~mm})$ was drilled above the hippocampus (anterior $=-3.3$ and lateral $=2.2 \mathrm{~mm}$ from bregma) for extra- and intracellular recordings. Pairs of stimulating electrodes $(100 \mu \mathrm{m}$ each, with 0.5 $\mathrm{mm}$ tip separation) were inserted into the left and right fimbria-fornix (anterior $=-1.3$, lateral $=1.0$, ventral $=4.1)$ to stimulate the COM input to the CA1 region. The cisterna magna was opened, and the cerebrospinal fluid was drained to decrease pulsation of the brain. Extracellular recording electrodes (three $20 \mu \mathrm{m}$ insulated tungsten wires) were inserted into the hippocampus to record field and unit activity from the CA1 pyramidal layer, stratum radiatum, and the dentate hilus. After the intracellular recording electrode was inserted into the brain, the bone window was covered by a mixture of paraffin $(50 \%)$ and paraffin oil $(50 \%)$ to prevent drying of the brain and decrease pulsation. The distance of the intracellular and extracellular electrodes was $0.5-1.0 \mathrm{~mm}$ in the anteroposterior and $0.2-0.5 \mathrm{~mm}$ in the lateral directions.

Micropipettes for intracellular recordings were pulled from $2.0 \mathrm{~mm}$ capillary glass. They were filled with $1 \mathrm{M}$ potassium acetate in $50 \mathrm{~mm}$ Tris buffer, containing also $3 \%$ biocytin for intracellular labeling. In vivo electrode impedances varied from 60 to $100 \mathrm{M} \Omega$. Once stable intracellular recordings were obtained, evoked and passive physiological properties of the cell were determined. Field activity was recorded through the extracellular electrode and filtered between $1 \mathrm{~Hz}$ and $5 \mathrm{kHz}$. After the physiological data had been collected, biocytin was injected through a bridge circuit (Axoclamp-2B) using $500 \mathrm{msec}$ depolarizing pulses at 0.5-2.0 $\mathrm{nA}$ at $1 \mathrm{~Hz}$ for 10-60 min (Li et al., 1994; Sik et al., 1995). After 2-12 hr postinjection survival times, the animals were given a urethane overdose and then perfused intracardially with $100 \mathrm{ml}$ physiological saline, followed by $400 \mathrm{ml}$ of $4 \%$ paraformaldehyde and $0.2 \%$ glutaraldehyde dissolved in PBS, pH 7.3. The brains were then removed and stored in the fixative solution overnight. Sixty-micrometer-thick coronal sections were cut and processed for biocytin labeling as described previously (Sik et al., 1995). In four experiments, the micropipette was broken $(<1 \mathrm{M} \Omega)$ and DC changes were measured in the CA1 pyramidal layer during epilepsy or $\mathrm{KCl}$-induced spreading depression.

Pressure ejection of $\mathrm{KCl}$. Extracellular DC shifts and spreading depression were induced by pressure ejection (Picospritzer, General Valve Co.) of $1 \mathrm{M} \mathrm{KCl}$ solution from a glass micropipette $(2-5 \mu \mathrm{m}$ tip diameter; Herreras et al., 1994). The pipette was placed $0.3-1.0 \mathrm{~mm}$ posterior to the intracellular microelectrode and also served for monitoring the local EEG.

\section{RESULTS}

In agreement with previous studies on stimulus-induced afterdischarges in the rat, several distinctive epochs could be recognized (Leung, 1987; Buzsáki et al., 1989b) which included: (1) a 20-60 sec primary afterdischarge of slow $(2-12 \mathrm{~Hz})$, fast $(30-120 \mathrm{~Hz})$, and ultrafast $(200-400 \mathrm{~Hz})$ oscillations; (2) a silent postictal depression period; and (3) a secondary afterdischarge. The animal sat or stood still throughout these events with occasional "wet dog" shakes occurring during the secondary afterdischarge and, rarely, during the later part of primary afterdischarge. EEG activity gradually recovered after these three distinctive epochs. However, substantial alterations could be recognized in the EEG for several hours (Leung, 1987).

The large amplitude events associated with afterdischarges can be recorded from various regions and layers of the hippocampus. A large part of these voltage traces is often a result of volume conduction from distant current generators. Thus, voltage traces are not always reliable for tracing the structural sources of the field events. CSD analysis provides a more precise localization for the origin of extracellular currents. The current that flows into the cells across an increased membrane conductance (an active inward current or sink) will exit at adjacent, inactive parts of the membrane (passive outward current or source) to return to the site of current entry by way of diverse paths through the extracellular medium. Conversely, active outward currents, generated by decreased membrane conductance, will create inward currents at the inactive parts of the membrane (passive sinks) by way of the extracellular return current. When extracellular potentials are simultaneously measured at various depths, the CSD derivatives of the voltage traces allow for the continuous monitoring of the exact anatomical locations of sinks and sources. Figure 1 illus- 


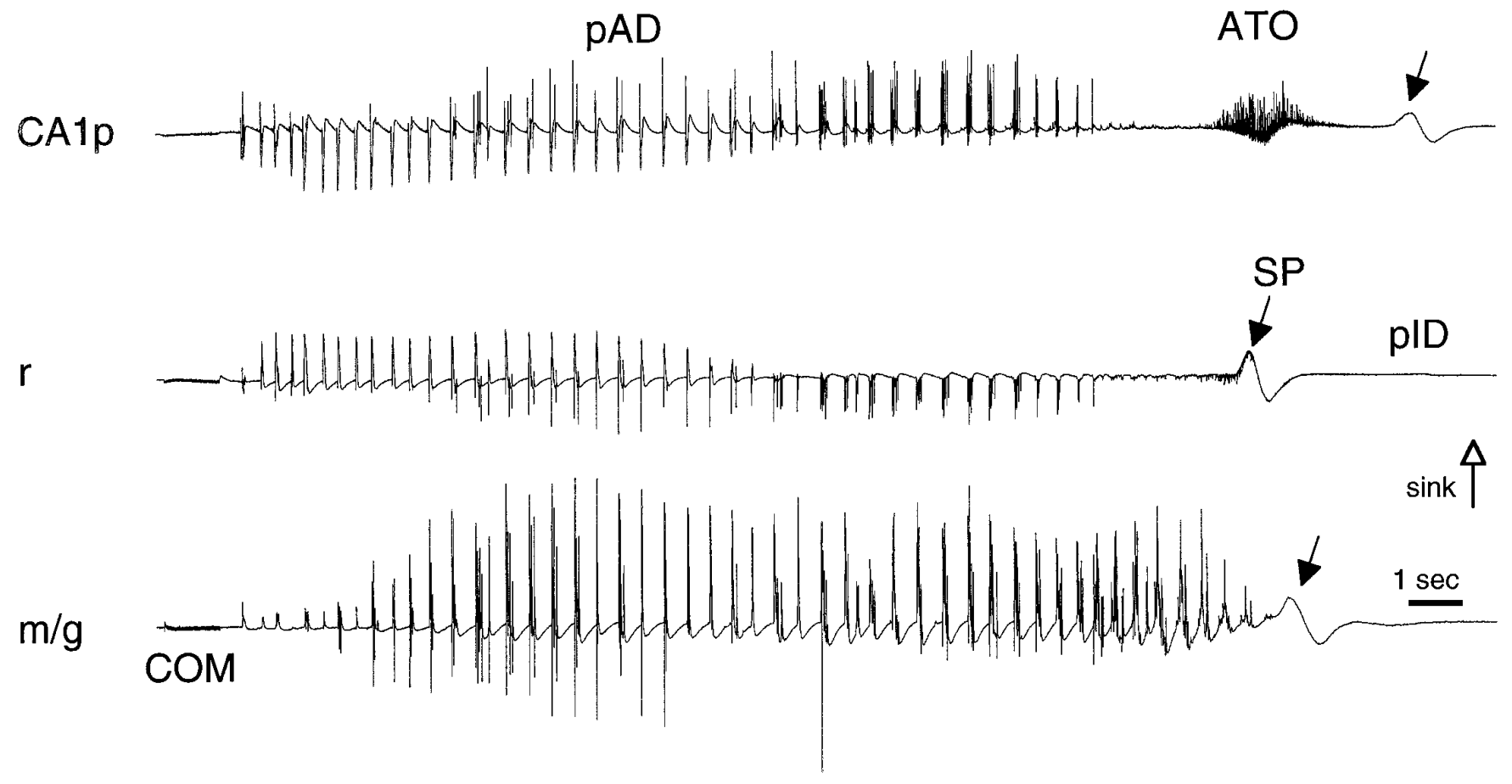

Figure 1. Main patterns of the afterdischarge in the hippocampus evoked by COM stimulation $(200 \mathrm{~Hz})$. The continuous voltage traces from 16 recording sites (1-2000 Hz bandpass) were used to calculate the CSD derivatives. Only three selected CSD traces from the CA1 pyramidal layer $(p)$, stratum radiatum $(r)$, and the supragranular layer $(\mathrm{m} / \mathrm{g})$ are shown here. Sinks are up. Arrows, Onset of the sustained potential $(S P)$ shifts recorded by the AC-coupled amplifiers; $p I D$, postictal depression. ATO, Afterdischarge termination oscillation. The primary afterdischarge (pad) shown here is omitted from the illustrations in Figures 2-4.

trates CSD traces during the course of an afterdischarge and the main events distinguished in the present work.

\section{Termination of the primary afterdischarge: ATO and sustained potentials}

The initiation and maintenance of the primary afterdischarge (pAD) have been described previously in an overlapping set of animals (Bragin et al., 1996). The evoked pAD was stereotypical both within and across animals, lasting for 30-40 sec (Buzsáki et al., 1989; Stringer et al., 1991; McNamara, 1994; Bragin et al., 1996). The pAD invariably terminated first in the CA1 region in all animals, regardless of whether the afterdischarge was induced by PP or COM stimulation (Fig. 1). The termination of afterdischarge was heralded by two physiological events: (1) large amplitude, slow potential drifts in the extracellular space and (2) the emergence of a low amplitude, fast $(40-90 \mathrm{~Hz})$ field oscillation (Figs. 1-3). Because the large extracellular DC shifts, recorded with glass electrodes (see below), were an order of magnitude larger than the amplitude of the fast oscillations, simultaneous recording of the two events with reliable amplitude resolution of the field oscillation and without exceeding the 12-bit resolution of the analog-digital converter was not always possible. Therefore, in the freely moving rat we studied the slow potential changes with slow time constant $(0.03$ and $0.1 \mathrm{sec})$ filter settings and less amplification. The two events could be recorded simultaneously by using faster time constants $(0.3$ or $1 \mathrm{~Hz})$ and thereby compromising the accuracy of the amplitude measurement of the slow potential (Fig. 1). Although in these records the magnitude of the DC shift-associated change could not be interpreted, the onset of the DC potentials in the various layers still could be recognized precisely.

\section{Sustained potentials}

Sustained (DC) potential shifts, typically associated with increases of $\left[\mathrm{K}^{+}\right]_{\mathrm{o}}$, often have been observed during electrically or chemically induced afterdischarges (Fertziger and Ranck, 1970; Heinemann et al., 1977; Somjen et al., 1985; Somjen and Giacchino 1985; Korn et al., 1987; Stringer et al., 1991; Wadman et al., 1992), as well as in human epileptic seizures (Ikeda et al., 1996). In agreement with previous studies in anesthetized animals (Somjen et al., 1985; Stringer et al., 1991; Wadman et al., 1992), DC shifts were present during $\mathrm{pAD}$, as indicated by the large negative polarity slow waves $(<0.5 \mathrm{~Hz})$ in the $\mathrm{AC}$-coupled records. In contrast to these relatively low amplitude slow potentials $(<5$ $\mathrm{mV})$, termination of $\mathrm{pAD}$ was associated with a large amplitude $(5-15 \mathrm{mV})$ negative shift of the baseline when using 0.03 or $0.1 \mathrm{~Hz}$ time contant. Figure 2 illustrates the terminal part of the pAD recorded at 16 sites in the CA1 dentate gyrus axis. The DC change, associated with the end of the afterdischarge in the CA1 region, occurred first in the apical dendritic layers, typically at the level of the distal dendrites, i.e., around the hippocampal fissure (Fig. $2 A$, electrode 8 ). The front of the DC shift (i.e., the negative peak of the AC-coupled slow wave) moved toward the CA1 pyramidal cell layer at a velocity of $0.1-0.2 \mathrm{~mm} / \mathrm{sec}$, as calculated from the time difference between the negative peaks of the slow waves and the distance between the recording sites in this and other animals ( $n=37$ afterdischarges in 9 rats). The wave sometimes failed to propagate across the cell body layers or was delayed by 3-5 sec before invading the pyramidal layer and stratum oriens (Fig. 3, black arrows). In several cases, the DC potential crossed the hippocampal fissure and moved toward the granule cell layer at the same propagation velocity as in the CA1 


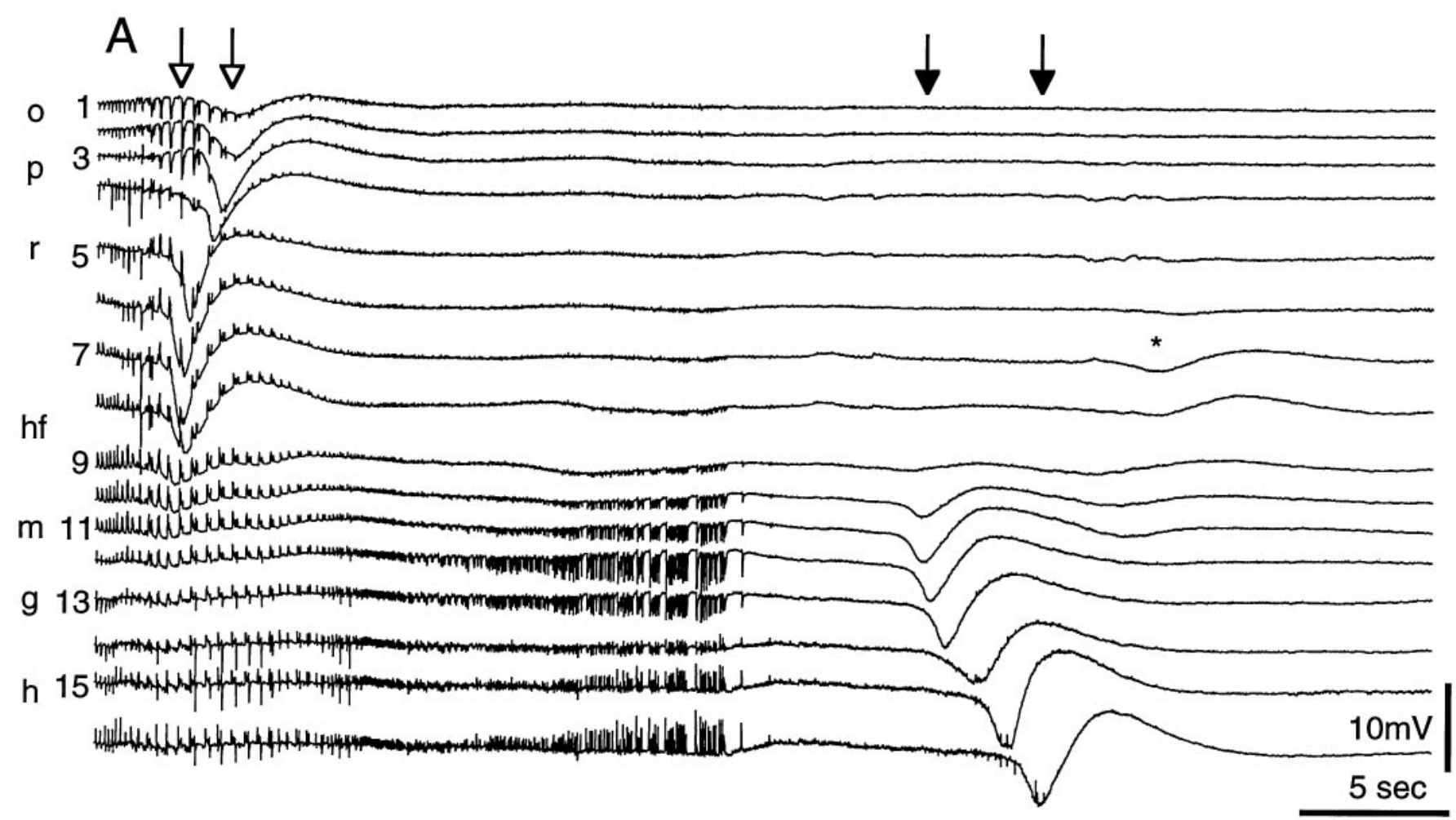

\section{B}

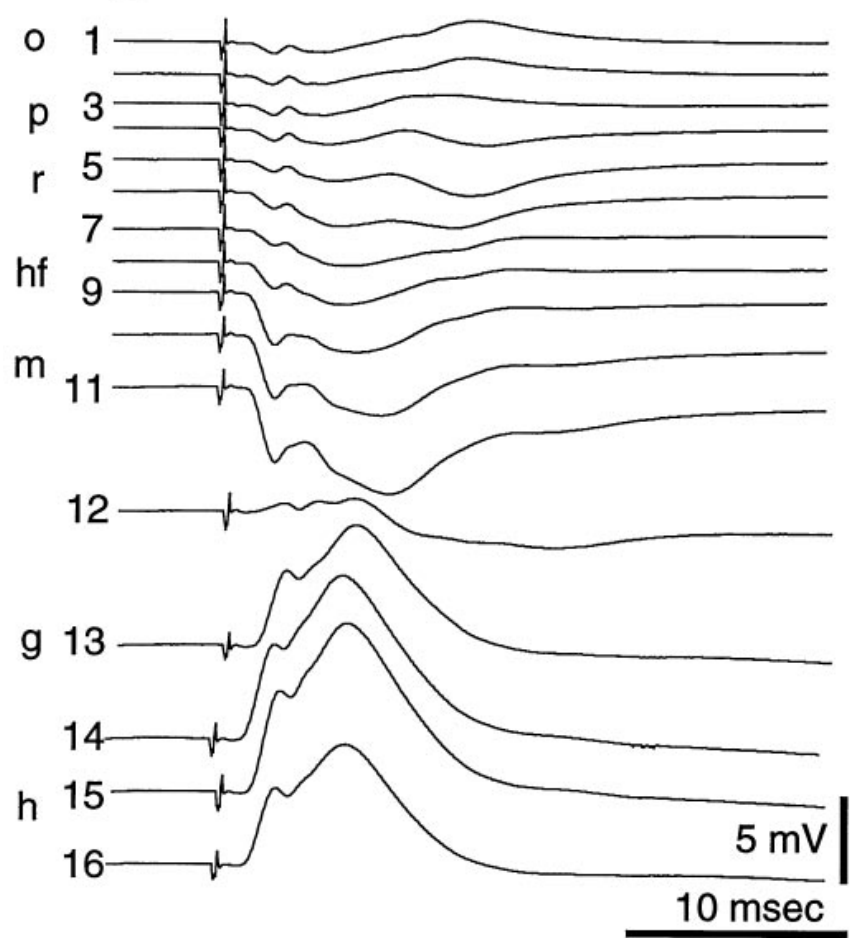

C

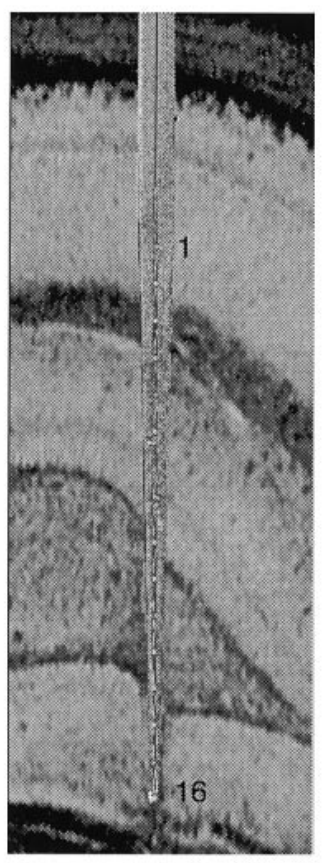

D

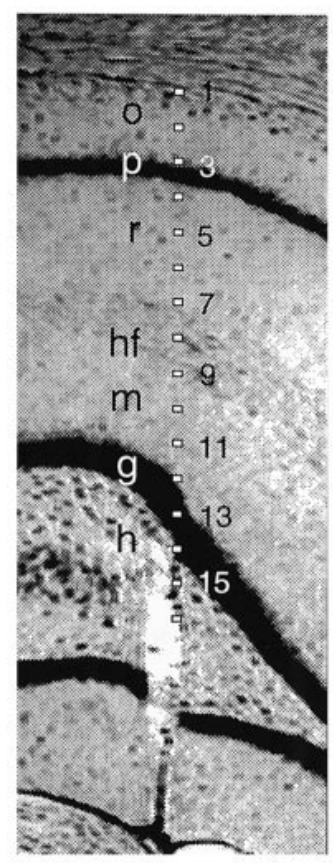

Figure 2. Sustained potentials associated with afterdischarge termination. $A$, Sixteen-site recording of an afterdischarge in the CA1-dentate gyrus axis in the awake rat. The early part of the pAD is omitted (see example in Fig. 1) to provide a better time resolution. Arrows above traces indicate the onset of large DC shifts recorded by AC-coupled amplifiers $(0.1-200 \mathrm{~Hz})$. ATO is not visible at this magnification and low sampling rate (200 Hz). The propagation speed of the DC front was $0.28 \mathrm{~mm} / \mathrm{sec}$ in the CA1 region (open arrows) and $0.12 \mathrm{~mm} / \mathrm{sec}$ in the dentate gyrus (filled arrows). Asterisk, A second wave of DC shift in the absence of neuronal activity. $B$, Evoked potentials in response to perforant path stimulation at the same recording position as $A$. $C$, Silicon probe in situ at its final recording position as seen during vibratome sectioning (different depth from $A$ and $B$ ). $D$, The same section as shown in $C$ after Nissl staining. Recording sites during the afterdischarge shown in $A$ are marked by 1 to 16 . The exact recording position of each site is determined from the laminar profile of the evoked potentials $(B) . o$, CA1 stratum oriens; $p$, CA1 pyramidal layer; $r$, stratum radiatum; $h f$, hippocampal fissure; $m$, molecular layer; $g$, granule cell layer; $h$, hilus. 


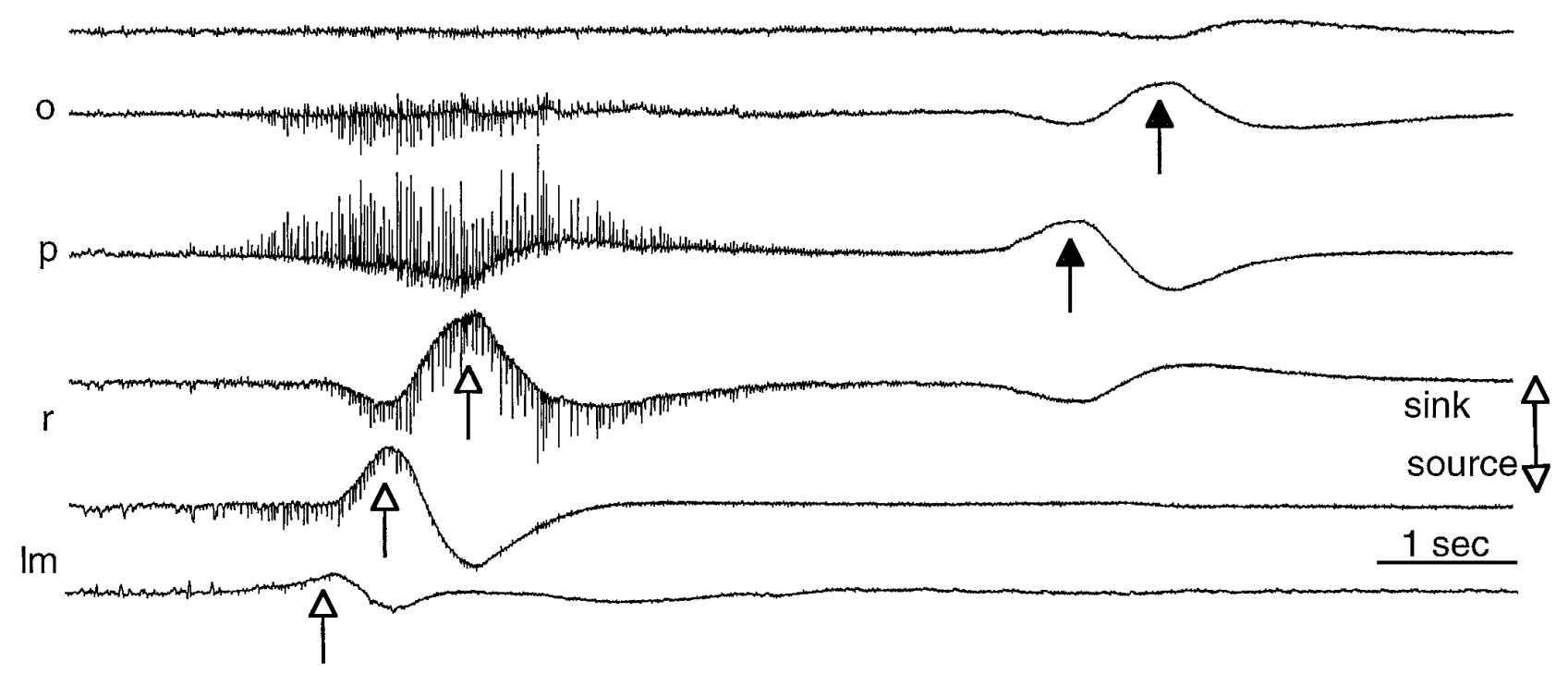

Figure 3. ATO and associated sustained potentials in the CA1 region. Only the end of the primary afterdischarge, induced by COM stimulation, is shown. Traces 1 to 6 are CSD derivatives of band-passed filtered EEG traces $(0.3 \mathrm{~Hz}$ to $2 \mathrm{kHz})$. Note the onset of the sustained potential in stratum lacunosum-moleculare and its slow $(0.15 \mathrm{~mm} / \mathrm{sec}$ ) spread toward the pyramidal layer (open arrows). Strata pyramidale and oriens were invaded after a $3 \mathrm{sec}$ delay ( filled arrows). Fast sinks of ATO waves are largest in the pyramidal layer, surrounded by sources in the strata radiatum and oriens. $o$, CA1 stratum oriens; $p$, CA1 pyramidal layer; $r$, stratum radiatum; $l m$, stratum lacunosum-moleculare.

stratum radiatum. In the dentate gyrus $/ \mathrm{CA} 3 \mathrm{c}$ area, termination of local afterdischarge was similarly associated with a large DC shift, after which the EEG activity became isoelectric (Fig. $2 A$ ). Occasionally, the afterdischarge termination DC wave was followed by another sustained potential shift of smaller amplitude $20-40 \mathrm{sec}$ later.

In a few cases, tetanic stimulation of either the COM or PP path elicited only a short-lived $(<5 \mathrm{sec})$ afterdischarge. In these cases, the fast oscillation and the associated slow potential shift were not observed. Instead, the abbreviated afterdischarge terminated simultaneously at all recording sites, and baseline activity returned quickly without a noticeable postictal depression period. The termination of these "aborted" afterdischarges is not considered further because they do not represent "full-blown" epileptic activity (McNamara, 1994) and they are not able to induce either "kindling" or status epilepticus (Goddard et al., 1969; Racine et al., 1972; Lothman and Williamson, 1993). Full-blown afterdischarges were "all-or-none" in nature because their pattern and duration after the first few elicitations were quite similar (Leung, 1987; Buzsáki et al., 1989b).

\section{Afterdischarge termination oscillation (ATO)}

The onset of the DC potential shift in the dendritic layers coincided with the development of a short-lived (1-3 sec) low amplitude, fast $(40-80 \mathrm{~Hz})$ field oscillation (Figs. 3, 4). Because of its relatively small amplitude $(0.5-4 \mathrm{mV}$ in the cell body layers), the field oscillation became apparent only at higher amplification of the EEG signal. We termed this low-amplitude fast rhythm afterdischarge termination oscillation (ATO). The ATO was first observable in the CA1 region. Initially, the fast waves of the ATO were interspersed between the large population spikes of the late part of pAD. The oscillatory waves were of opposite polarity across the pyramidal cell layer. The amplitude of the fast oscillatory waves and associated population spikes varied in a waxing/ waning pattern, giving a "spindle" appearance at a slower recording speed (Fig. 4).

CSD analysis revealed that the ATO emerged in the stratum radiatum and moved slowly $(0.1-0.2 \mathrm{~mm} / \mathrm{sec})$ toward the cell body layer (Fig. $4 A$ ). In the pyramidal layer, the negative peaks of the fast waves were associated with population spikes of $0.5-3 \mathrm{mV}$ in amplitude. In the CSD records, the large rhythmic sinks in the pyramidal layer were coupled to corresponding sources in the stratum radiatum (Figs. 3, 4). Occasionally, rhythmic sources in the stratum radiatum were disproportionally larger than the surrounding sinks in the vertical plane. We assume that in such cases the sources reflected passive return currents for active sinks generated rostrally or caudally from the recording site.

ATOs were also observed in the granule cell layer and in the CA3 pyramidal layer (Fig. 4B, C). ATO emerged significantly later in these regions, in accordance with their longer duration of $\mathrm{pAD}$ (Bragin et al., 1996). The shape, duration, and frequency of ATO in these regions were similar to that described in the CA1 pyramidal cell layer. Whereas ATO was always present in the CA1 region, it was observed in only 50 and $30 \%$ of afterdischarges in the CA3 and dentate regions, respectively.

The propagation speed of ATO in the septohippocampal direction was examined in animals equipped with 6-shank probes $(300$ $\mu \mathrm{m}$ intershank intervals) implanted parallel to the long axis of the hippocampus. Three to four of the six shanks could often be inserted into the cell body layer at the same depth. Figure 5, $A$ and $B$, illustrates slowly migrating ATOs in the CA1 region and dentate hilar area of the same rat, respectively. From the distances of the recording tips and the time differences of the peaks of the ATOs envelopes, the propagation of ATO in the longitudinal direction varied from 0.1 to $0.18 \mathrm{~mm} / \mathrm{sec}(n=3$ rats).

\section{Unit activity in awake animals}

Isolated neurons with $>5 \mathrm{~Hz}$ spontaneous discharge frequency, and with repetitive spikes in response to either PP or COM stimulation, were classified as putative interneurons, whereas slow firing cells with occasional complex spike bursts were identified as pyramidal cells (Fox and Ranck, 1981; Buzsáki et al., 1983). Discharge of all isolated pyramidal cells $(n=7)$ was phase locked to the negative component of ATO, typically in an intermittent 

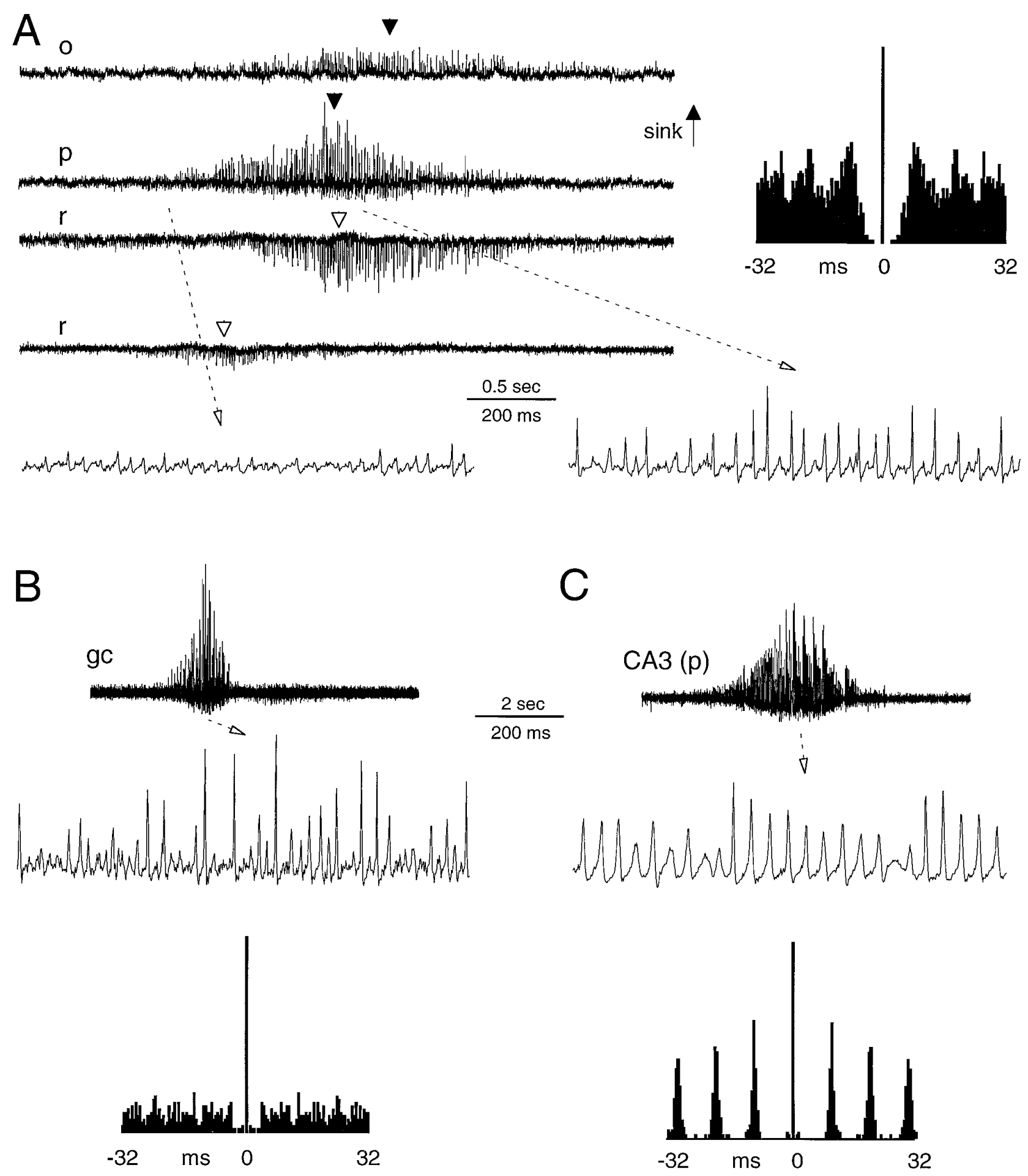

Figure 4. ATO in different hippocampal regions. $A$, CSD traces of ATO $(1-2000 \mathrm{~Hz})$ in the CA1 region. $o$, Stratum oriens; $p$, pyramidal layer; $r$, stratum radiatum. Open and filled arrowheads indicate slow upward movement of the sources and sinks, respectively. Sinks are up. $B$, CSD trace in the granule cell layer. $C$, CSD trace in the CA3c pyramidal layer. The ATOs shown in CA1 $(A)$, granule cell layer $(B)$, and CA3 pyramidal layer $(C)$ occurred 19,25 , and $41 \mathrm{sec}$ after afterdischarge onset in the same rat, respectively. The expanded sweeps reveal the fast field oscillations with and without population spikes. Histograms, autocorrelograms of ATO.

fashion. When population spike components, riding on ATO, grew substantially, separation of single cells became impossible. Multiple unit discharges of pyramidal cells, however, continued to discharge on the negative peaks of the local fast waves. Four putative interneurons were encountered in the CA1 pyramidal cell layer and 21 interneurons in the hilar region. Eighteen of the hilar cells underwent a substantial amplitude decrease and stopped discharging altogether before the population spike burst phase of the pAD (Bragin et al., 1996). The firing frequency of the remaining CA1 and hilar interneurons also decreased substan- 

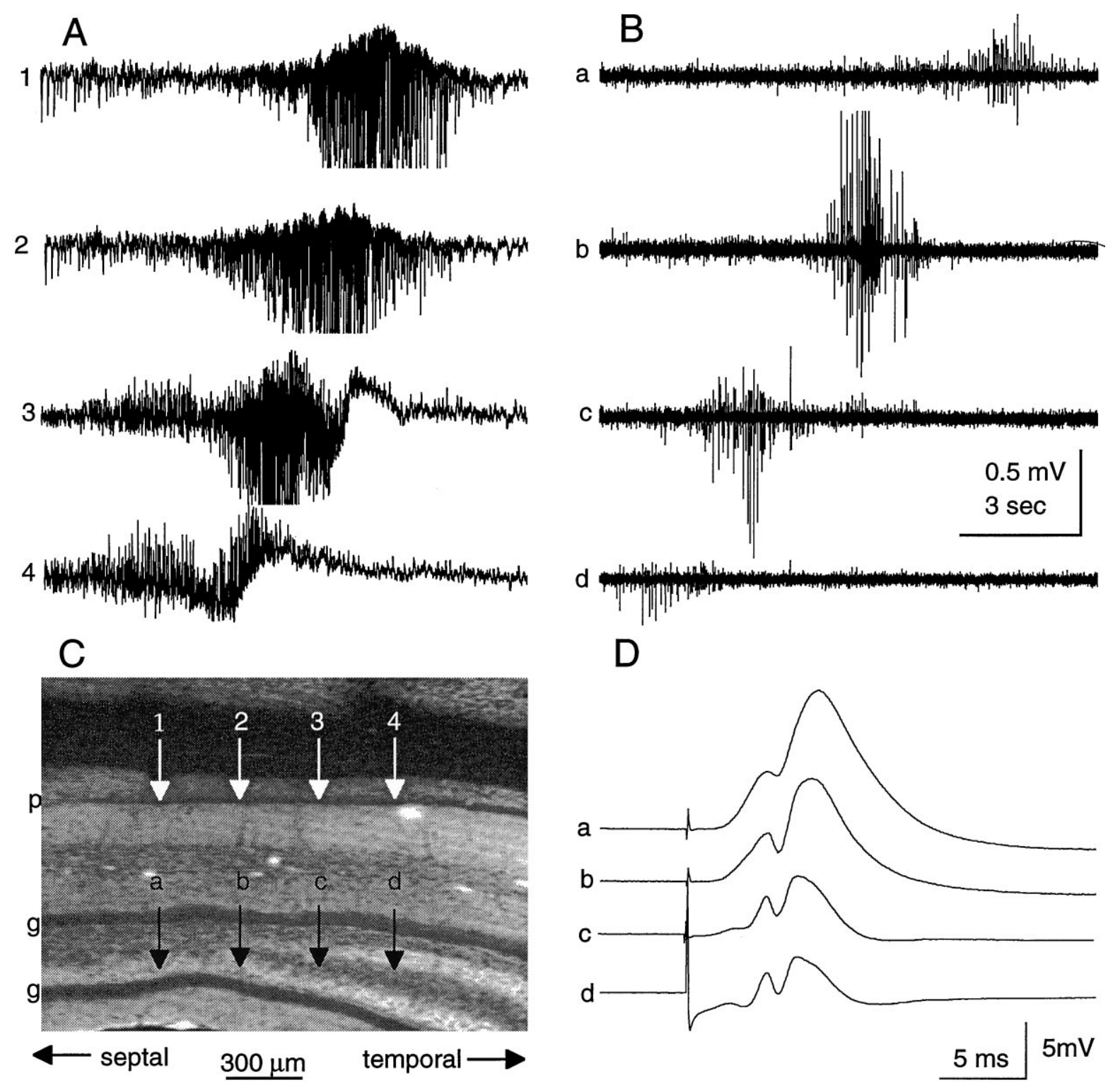

Figure 5. Longitudinal spread of the ATO in the CA1 region $(A)$ and dentate hilar region $(B)$. $A$, Simultaneous recordings from four shanks in the pyramidal layer (voltage traces). Population spikes are clipped. $B$, Simultaneous recordings from four hilar sites. $C$, Approximate recording sites in the CA1 region (white arrows) and hilar region (black arrows) indicated on a section cut parallel to the septotemporal axis of the hippocampus. $D$, Evoked potentials in the hilar region in response to perforant path stimulation. Note slow spread of ATO $(0.1 \mathrm{~mm} / \mathrm{sec}$ in CA1; $0.2 \mathrm{~mm} / \mathrm{sec}$ in hilus $)$ in the temporoseptal direction $(A, B)$ but synchronously occurring evoked population spikes $(D)$. $p$, Pyramidal layer; $g$, granule cell layer.

tially during the population spike phase of the pAD, and only a single CA1 interneuron continued to discharge during ATO (Fig. 6). On the waxing part of the ATO, this cell fired on the negative peaks of the local oscillatory waves. However, even this neuron ceased to fire after population spikes began to dominate the ATO. These observations suggest that interneurons do not play a significant role in the generation of ATO.

\section{Intracellular observations}

The pattern of pAD was somewhat different under deep anesthesia, and significantly larger current intensities and longer trains were required to induce afterdischarges than in the drug-free rat (Bowyer and Winters, 1981; Somjen et al., 1985; Stringer et al., 1991; Wadman et al., 1992). Long duration pADs with repetitive population bursts, comparable to those in the awake animal, were rarely observed. The more frequently elicited brief afterdischarges terminated abruptly and the EEG returned to its baseline pattern in 5-10 sec. ATO was observed only when long lasting afterdischarges $(>15 \mathrm{sec})$ were induced.

Intracellular recordings from CA1 pyramidal cells $(n=6)$ revealed a large depolarization of the soma membrane $(-40$ to $-20 \mathrm{mV}$ ) during COM stimulation. Neuronal discharge resumed only after the cell membrane became sufficiently repolarized. Spike bursts and single spikes occurred in conjunction with the population bursts recorded by the extracellular metal electrode (Fig. 7A). Intracellularly, ATO was associated with a subthreshold oscillation of the membrane potential (Fig. $7 B$ ). Small amplitude depolarizing waves at the ATO frequency were observed at various voltage levels of the membrane. As the soma became more depolarized, action potentials emanated from the depolarizing peaks of the fast oscillatory waves. After a series of fast action 


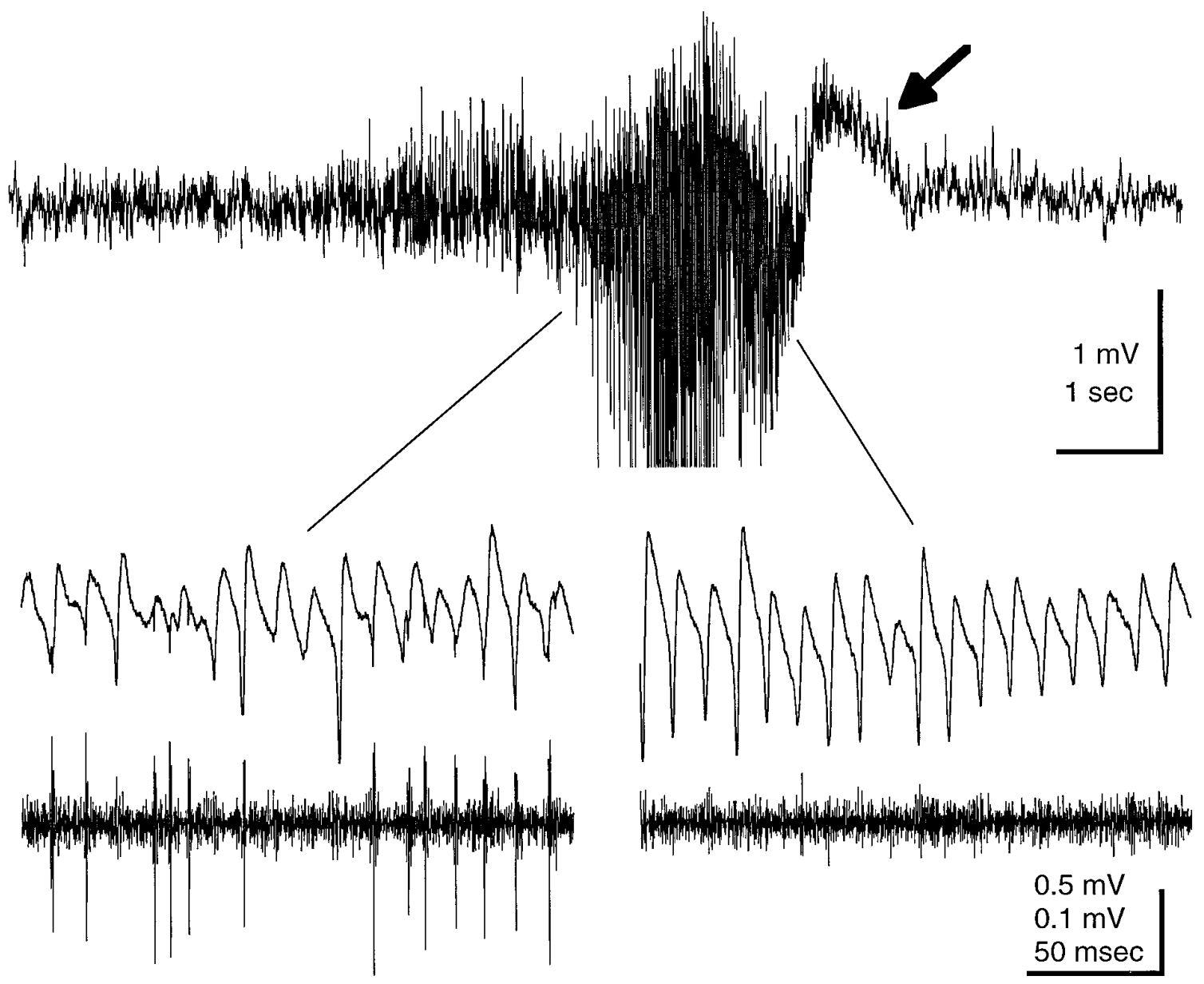

Figure 6. Interneuronal activity during the ATO. Top trace, Voltage trace recorded from the CA1 pyramidal layer (wide band; $1 \mathrm{~Hz}$ to $5 \mathrm{kHz}$ ). Negative peaks were clipped. Arrow, Slow wave reflecting the onset of the extracellular DC shift. Shorter epochs of the wide band trace (middle) and their high-pass-filtered $(0.5-5 \mathrm{kHz}$; bottom) derivatives are shown at faster speed below. Note relatively rhythmic firing of the interneuron at the beginning of ATO (left) and its complete silence on the waning phase (right).

potentials, the membrane potential suddenly depolarized to between -30 and $-10 \mathrm{mV}$, signaling the end of the extracellular ATO. When the extracellular electrode was placed close $(<0.5$ $\mathrm{mm}$ ) to the intracellular pipette, the intracellular oscillation and extracellular ATO occurred virtually simultaneously, and the large depolarization shift intracellularly coincided with the waning phase of the extracellular ATO and a slow potential change in the extracellular $\mathrm{AC}$-coupled trace (Fig. 7A). With larger interelectrode distances, the intracellular fast action potential burst and the associated large membrane depolarization could either follow (Fig. 8) or precede the extracellular ATO. In some cases, the first depolarization shift was followed by another depolarization wave, and the membrane potential returned to the baseline only after several minutes (Fig. 8). In summary, the intracellular experiments revealed fast membrane oscillation and spiking in association with the extracellular ATO. The onset of the sustained potential changes in the extracellular milieu corresponded to a large intracellular depolarization of pyramidal cells and a consequent block of their firing. Recordings with extracellular glass pipettes in the pyramidal layer confirmed that the AC-recorded slow potential and the intracellularly recorded large depolarization at the end of the afterdischarge corresponded to a large (10-20 mV) negative DC shift (see also Somjen et al., 1985).

The afterdischarge-induced ATO and intracellular depolariza- tion could be mimicked by extracellular injection of $\mathrm{KCl}$ into the CA1 stratum radiatum $(n=5$ cells; Fig. $7 C)$. The frequency and shape of the extracellularly recorded fast oscillation were identical to those studied by Herreras et al. (1994) in detail (not shown). The speed and magnitude of the intracellular depolarization were similar to the afterdischarge-induced changes. The propagation velocity of the $\mathrm{KCl}$-induced DC shift, calculated from the time difference between the onset of the sustained potential at the $\mathrm{KCl}$-containing pipette and the onset of the large intracellular depolarization and the distance between the extracellular and intracellular electrodes, was $0.1-0.2 \mathrm{~mm} / \mathrm{sec}$. Furthermore, extracellular recordings with glass micropipettes had shown that the magnitude of the KCl-induced DC shift in the extacellular space $(5-20 \mathrm{mV})$ was similar to that observed during electrical stimulation-induced afterdischarges associated with ATO.

\section{DISCUSSION}

The principal findings of the present experiments are that termination of primary afterdischarge in vivo is associated with the occurrence of a large DC shift in the dendritic layers and fast field oscillation in the cell body layers. These pathophysiological events spread at a very low speed in the three-dimensional space of the hippocampus. In intracellular recordings, these changes correlated with a large depolarization and fast discharge of CA1 


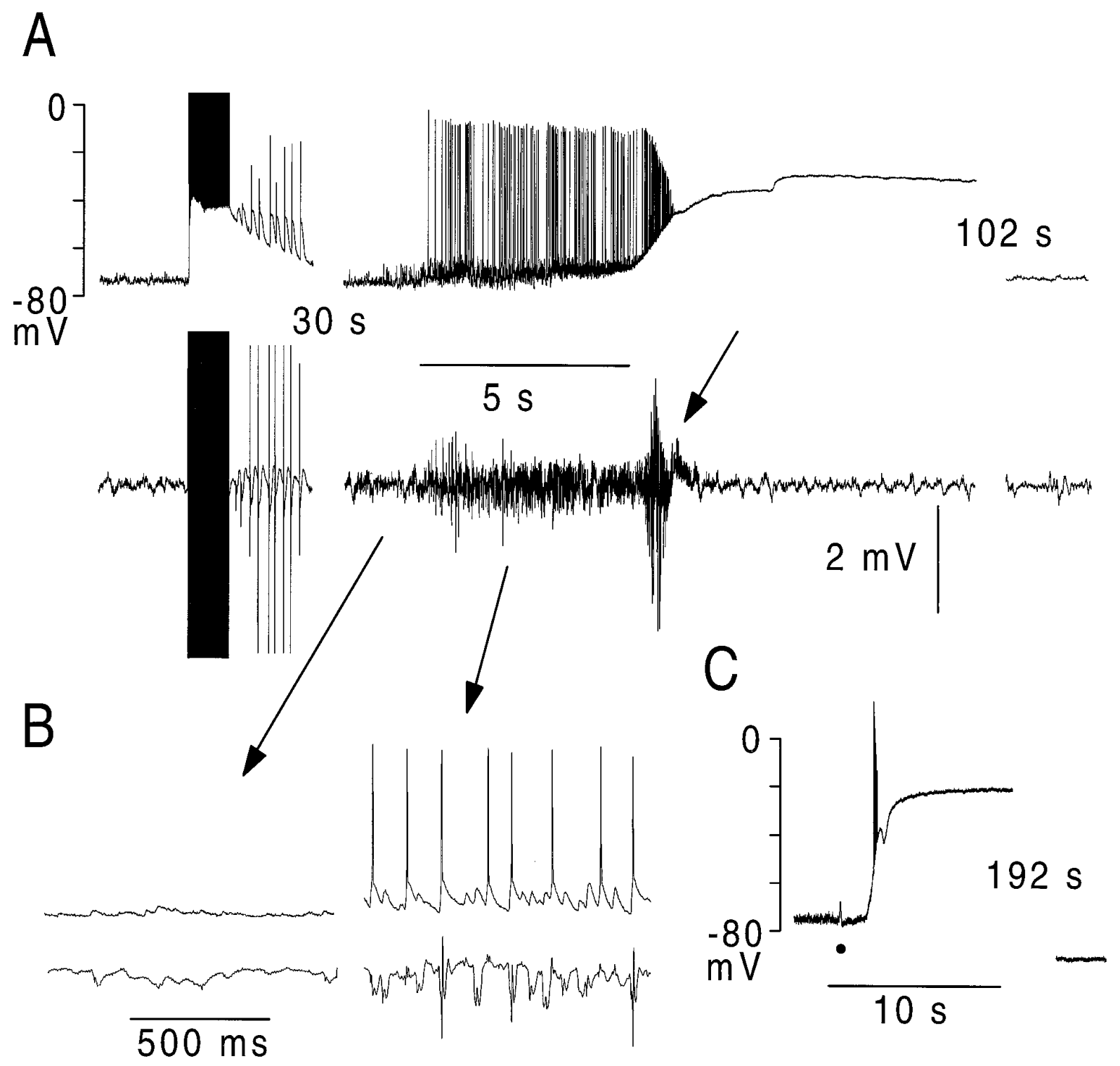

Figure 7. Intracellular correlates of the ATO and sustained potential shift in a CA1 pyramidal neuron. $A$, COM-induced afterdischarge in the urethane anesthetized rat recorded intracellularly (top trace) and field activity (bottom trace) recorded $<0.5 \mathrm{~mm}$ posterior to the micropipette. Thirty seconds are omitted between traces $(30 \mathrm{~s})$. Note fast spike burst and depolarization block of the cell and associated with extracellular ATO and the onset of the extracellular DC potential shift (arrow above field trace). Extracellular trace was wide-band-filtered (1 Hz to $5 \mathrm{kHz}$ ). Resting membrane potential was restored after $102 \mathrm{sec}$ (last trace segment). B, Details of records in $A$ (arrows) at faster speed. Note fast depolarizing potentials and action potentials during ATO. C, Depolarization block could be mimicked by extracellular injection of KCl. Recovery occurred after 192 sec. In other experiments, KCl induced fast field oscillations (ATO) and a 5-30 mV negative DC shift in the pyramidal cell layer (not shown).

pyramidal neurons. The findings suggest that stimulation-induced afterdischarges are terminated by a depolarization blockade of principal cells.

\section{ATO}

Fast field oscillations in the gamma frequency range $(40-100 \mathrm{~Hz})$ have been described in association with hippocampal theta activity after entorhinal cortex lesion and in the recovery phase of induced afterdischarges (Stumpf, 1965; Leung, 1982; Buzsáki et al., 1983; Bragin et al., 1995b; Charpak et al., 1995). The theta-associated gamma oscillation is believed to reflect rhythmic hyperpolarization of the pyramidal cell membrane as a result of a network oscillation of basket interneurons (Buzsáki et al., 1983; Soltész and Dechenes, 1993; Bragin et al., 1995; Whittington et al., 1995;
Traub et al., 1996; Wang and Buzsáki, 1996). The afterdischargeinduced late oscillation (Leung, 1987) and the gamma pattern induced by entorhinal cortex lesion (Bragin et al., 1995b) emerge in the CA3 region and are transferred to the CA1 region by the Schaffer collaterals (G. Buzsáki and A. Bragin, unpublished observations). Although the frequency of ATO is similar to these gamma patterns, several observations suggest that its mechanism may be distinct.

A major difference between ATO and the naturally present, theta-associated gamma rhythm is the absence of interneuronmediated inhibition in ATO. In our sample, all but one interneuron ceased discharging before the occurrence of ATO, and none of them fired during the waning part of the ATO spindle. Al- 


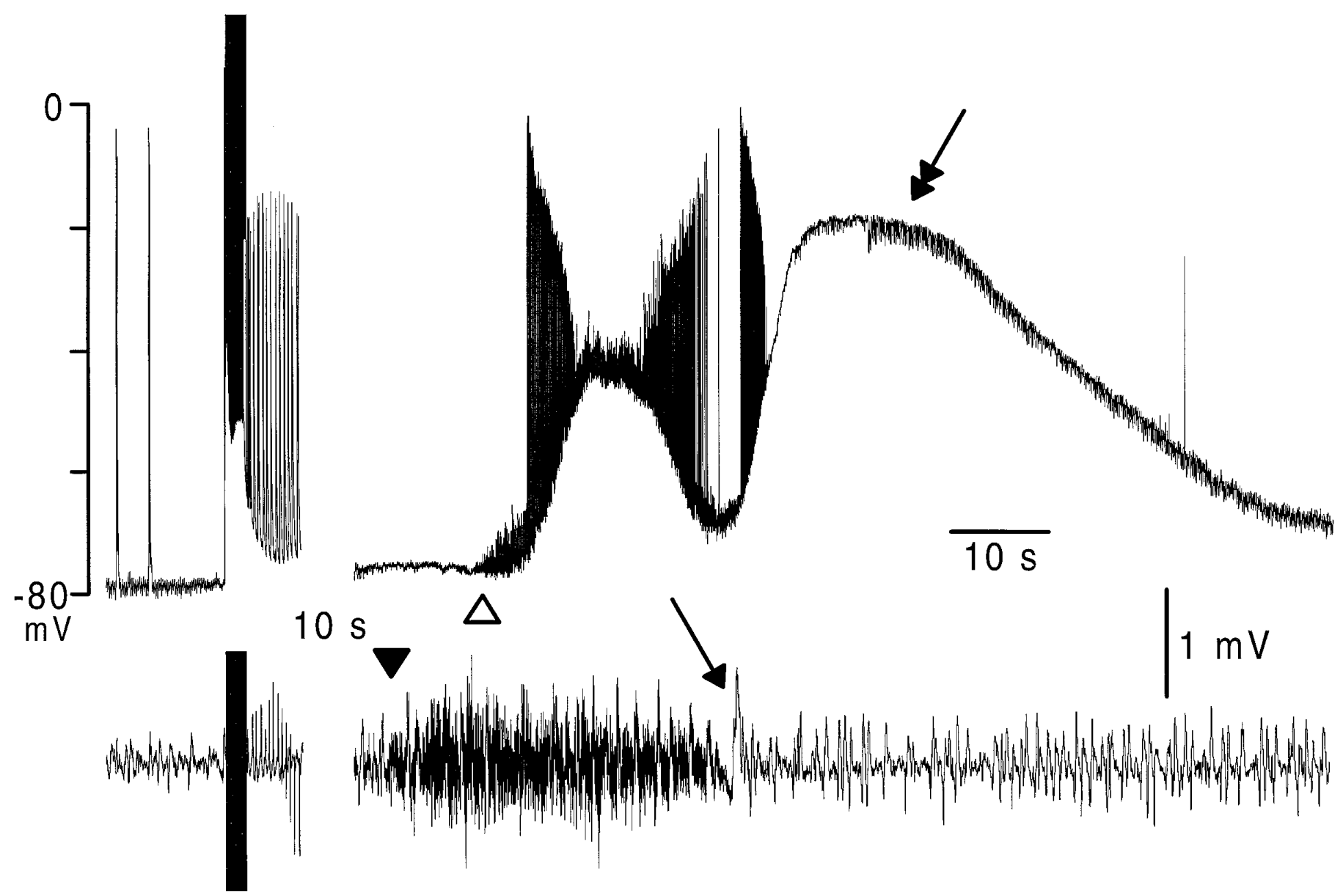

Figure 8. Intracellular correlates of the ATO in a pyramidal neuron at the CA1-subicular border. COM-induced afterdischarge recorded intracellularly (upper trace) and field activity (bottom trace) recorded $\sim 1 \mathrm{~mm}$ posterior to the micropipette in the CA1 pyramidal layer. Ten seconds $(10 \mathrm{~s})$ were omitted between the traces. Note fast membrane oscillation (open triangle), spike burst, and large depolarization $\sim 10$ sec after the onset of the extracellular ATO (black triangle). Note also a secondary depolarization wave (double arrow). Whereas actions potentials reoccurred on the descending part of the first depolarization wave, only a single action potential was observed on the falling phase of the second wave. The extracellular trace was wide-band-filtered $(1 \mathrm{~Hz}$ to $5 \mathrm{kHz})$. Arrow above field trace, Slow wave indicating the beginning of extracellular DC potential shift.

though it is possible that we failed to record from a critical group of interneurons responsible for the maintenance of ATO, several findings argue against such a possibility. First, pyramidal cells and the recorded interneurons fired on the same negative peaks of the ATO waves. Second, the field rhythm was associated with depolarizing potentials rather than IPSPs. Third, in accord with the intrasomatic events, CSD analysis of ATO revealed large sinks (inward currents), rather than sources, in the pyramidal cell layer. The somatic sinks during ATO could be regarded as "active" because they were associated with discharges of neurons both in the extracellular experiments in awake rats and in the intracellular experiments in anesthetized animal. In contrast, the physiological gamma pattern is characterized by rhythmic sources in the cell body layer (Bragin et al., 1995b).

ATO is also different from lesion-induced gamma oscillations (Bragin et al., 1995b) or from the fast EEG pattern that occurs during the late recovery part of an afterdischarge (Leung, 1987). These rhythms are generated in the CA3 region and transferred to the CA1 region by the Schaffer collaterals, as reflected by a sink source dipole in the strata radiatum and pyramidale, respectively. This dipole pattern is quite different from the sink source distribution associated with ATO. Most important, ATO occurred in the CA1 region in the absence of a concurrent gamma frequency rhythm in the CA3 area.

Intracellularly, the oscillatory waves corresponded to depolarizations from which action potentials emanated. In principle, the depolarizing potentials may correspond to EPSPs brought about by the very sparse recurrent excitatory collaterals among CA1 pyramidal cells themselves (Christian and Dudek, 1988; Radpour and Thomson, 1991; Klishin et al., 1995). Because the sparse recurrent collaterals terminate in the basal dendrites (Deuchars and Thomson, 1996), an active sink would be expected in this layer rather than in the pyramidal layer. Generation of ATO by the local recurrent collaterals is not supported by previous findings either. Field oscillation and intracellular membrane potential changes, virtually identical to ATO, could be provoked by extracellular potassium injection, confirming previous observations (Herreras et al., 1994). It is important to note that, in the experiments of Herreras et al. (1994), the fast field oscillation and the accompanying spreading depression were not prevented by blocking all synaptic activity with divalent cations. Ephaptic (transmembrane) effects may be a candidate mechanism for neuronal synchronization (Jefferys and Haas, 1982; Taylor and Dudek, 1982). Indeed, during the peak of the ATO spindle the voltage gradient 
across the cell body layers exceeded $15-25 \mathrm{mV} / \mathrm{mm}$, a value sufficient to affect the excitability of pyramidal cells in vitro (Jefferys, 1981). Yet another possibility is that the field ATO does not reflect true synchrony of pyramidal cells. Instead, the transiently increased number of discharging pyramidal cells at similar frequencies may result in a spurious field rhythm even when they fire randomly (Wang and Buzsáki, 1996).

\section{Termination of primary afterdischarge by spreading depolarization}

Several features of the sustained potentials, associated with the termination of pAD, were identical with those of spreading depression (Leao, 1944). The sustained potential after the pAD was invariably initiated in the dendritic layers, around the hippocampal fissure. The front of the wave traveled very slowly (0.1-0.2 $\mathrm{mm} / \mathrm{sec}$ ) in all directions, regardless of the anatomical connections of neurons. The wave spread toward the CA1 pyramidal layer and granule cell layer, as well as in the longitudinal axis, with a similar speed. Pyramidal cells discharged at a high frequency and time locked to the local extracellular ATO. It has been suggested that $\mathrm{KCl}$-induced fast oscillation and spreading depression is brought about by opening of gap junctions among principal cells (Czéh et al., 1993; Herreras and Somjen, 1993; Herreras et al., 1994). However, gap junctions have not yet been identified among pyramidal cells in the adult hippocampus (Katsumaru et al., 1988; Penttonen et al., 1995; T. F. Freund and P. Somogyi, personal communication). It is possible that epileptic afterdischarges and the resulting changes in the extracellular/intracellular milieu (Green, 1964; Pedley et al., 1976; Korn et al., 1987; Haglund and Schwartzkroin, 1990) create favorable conditions for a rapid de novo formation of gap junctions among pyramidal neurons (Perez-Velazquez et al., 1994; Penttonen et al., 1995). Such possibility, however, has yet to be demonstrated.

Depolarization-induced blockade of neuronal activity was not directly demonstrated in awake animals but was only inferred from the lack of neuronal activity after ATO. Excitability tests in response to single pulse stimulation of hippocampal afferents/ efferents provide indirect support for the depolarization blockade hypothesis, however. Single pulses, capable of inducing large amplitude $(>5 \mathrm{mV})$ orthodromic or antidromic population spikes before the afterdischarge, failed to induce any responses after the ATO (A. Bragin and G. Buzsáki, unpublished observations). A parsimonious explanation of the response failure is the loss of input resistance as a result of severe depolarization (Haglund and Schwartzkroin, 1984).

\section{Comparisons with previous studies}

The large DC shift and the associated ATO were consistent and integral parts of the stimulation-evoked afterdischarge in awake rats. This is in apparent contrast to the lack of previous observations of these events in the numerous reports using in vivo and in vitro epilepsy models. Several differences between those experiments and the present investigation might account for this discrepancy. First, electrical activity in awake animals has been recorded typically with electrodes the diameter of which is larger than the width of the CA1 pyramidal layer $(60 \mu \mathrm{m})$; therefore, the ATOs may have been shunted even if the electrode was positioned in the layer. The sustained potentials were eliminated by high-pass filters or regarded as movement artifacts. Second, the duration and intensity of population bursts during pAD may not be sufficient to induce these changes under anesthesia (Somjen et al., 1985; Stringer et al., 1991). Third, the short duration of the afterdischarges in in vitro models may offer a similar explanation for the lack of an ATO in these models. Finally, continuous perfusion of the slice may prevent excessive accumulation of $\left[\mathrm{K}^{+}\right]_{\mathrm{o}}$ and/or glutamate responsible for the depolarization of neurons.

These caveats notwithstanding, both DC shifts and ATO can be recognized in several published reports (Somjen and Giacchino, 1985; Somjen et al., 1985; Leung, 1987; Stringer et al., 1991). After long afterdischarges ( $>10 \mathrm{sec})$, ATO coincided with "an episode of Leao's depression" in urethane-anesthetized rats (Fig. 2 in Somjen et al., 1985), during which $\left[\mathrm{K}^{+}\right]_{\mathrm{o}}$ reached $40 \mathrm{~mm}$ (Fig. 1 in Somjen and Giacchino, 1985). When the duration of the afterdischarge was prolonged by repeated stimulation, spreading depression often blocked electrical activity in anesthetized, paralyzed rats (Wadman et al., 1992). Finally, depolarization blockade of spike discharge has been observed in vitro as well (Haglund and Schwartzkroin, 1984; Psarropoulou and Avoli, 1993; Gloveli et al., 1995; R. Dingledine and N. Lambert, personal communication).

\section{Neuron-glia communication and afterdischarge termination: a hypothesis}

The origin of ATO in the distal dendritic layers, the very slow spread of the associated sustained potential shift across the principal cell layers, and its similar propagation speed in all regions of the hippocampus suggest the involvement of the glial network. This contention is strongly supported by the occurrence of secondary slow potentials during the postictal depression period in the absence of neuronal activity. The importance of the intimate relationship between glia and neurons in the hyperexcitable tissue has long been recognized (Traynelis and Dingledine, 1988; Haglund and Schwartzkroin, 1990). Astrocytes are known to form a quasisyncytium via multiple gap junctions, and their density is lower in the pyramidal and granule cell layers (Takato and Goldring, 1979; Ransom, 1995). Neuronal activity-associated release of $\mathrm{K}^{+}$and/or glutamate can induce propagating $\mathrm{Ca}^{2+}$ waves in astrocyte cultures (MacVicar, 1984; Cornell-Bell et al., 1990; Dani et al., 1992) at a speed identical to spreading depression and the propagation velocity of ATO. Intercellular coupling through gap junctions is required for both propagating $\mathrm{Ca}^{2+}$ waves and spreading depression (Martins-Ferreira and Ribeiro, 1995; Nedergaard et al., 1995). The traveling $\mathrm{Ca}^{2+}$ waves, in turn, can trigger calcium influx into neurons (Nedergaard, 1994; Parpura et al., 1994; Nedergaard et al., 1995). We hypothesize that a similar glia-neuron dialogue in vivo may be responsible for the induction of ATO and depolarization blockade of principal cells (Fertziger and Ranck, 1970; Sypert and Ward, 1971; Leao, 1972; Heinemann et al., 1977; Haglund and Schwartzkroin, 1984). The increased $\left[\mathrm{K}^{+}\right]_{\mathrm{o}}$, resulting from intensive neuronal activity during the $\mathrm{pAD}$, may trigger propagating waves in the astrocytic network reflected by the slowly spreading sustained potentials. In turn, astrocytes at the front of the propagating depolarization wave release more potassium (Kuffler and Nicholls, 1966; Quandt and MacVicar, 1986), resulting in a large depolarization of neurons. The ensuing depolarization block of spike generation contributes to the termination of the afterdischarge and is regarded as the cause of the consequent postictal depression of the EEG (Sypert and Ward, 1971). The in vitro observation that the CA1 area has the least effective $\mathrm{Na}^{+}-\mathrm{K}^{+}$pump and the highest susceptibility to spreading depression (Haglund and Schwartzkroin, 1990; Schweitzer et al., 1992) may explain why afterdischarges always terminate in this hippocampal region.

From the above perspective, the DC potential shift and the 
ATO reflect depolarization of the glial network and neuronal population, respectively. The depolarization wave of the glial syncytium is thus both a prerequisite and cause of ATO. In summary, interaction between the glial syncytium and neuronal population seems critical for the termination of stimulationinduced afterdischarges in the intact brain. It remains to be established whether the $\mathrm{pAD} \rightarrow \mathrm{DC}$ wave $\rightarrow$ ATO $\rightarrow$ afterdischarge sequence reflects causal relationships and whether ATO and the associated depolarization block of neurons are present in other in vivo seizure models as well.

\section{REFERENCES}

Amaral D, Witter M (1989) The three-dimensional organization of the hippocampal formation: a review of anatomical data. Neuroscience 31:571-591.

Bowyer JF, Winters WD (1981) The effects of various anesthetics on amygdaloid kindled seizures. Neuropharmacology 20:199-209.

Bragin A, Jandó G, Nádasdy Z, Hetke J, Wise K, Buzsáki G (1995) Gamma (40-100 Hz) oscillation in the hippocampus of the behaving rat. J Neurosci 15:47-60.

Bragin A, Csicsvary J, Penttonen M, Buzsáki G (1997) Epileptic afterdischarge in the hippocampal-entorhinal system: current source density and unit studies. Neuroscience 76:1187-1203.

Buzsáki G, Leung L, Vanderwolf CH (1983) Cellular bases of hippocampal EEG in the behaving rat. Brain Res Rev 6:139-171.

Buzsáki G, Bickford RG, Ryan LJ, Young S, Prohaska O, Mandel RJ, Gage FH (1989a) Multisite recording of brain field potentials and unit activity in freely moving rats. J Neurosci Methods 28:209-217.

Buzsáki G, Ponomareff LG, Bayardo F, Ruiz R, Gage FH (1989b) Neuronal activity in the subcortically denervated hippocampus: a chronic model for epilepsy. Neuroscience 28:527-538.

Charpak S, Pare D, Llinás RR (1995) The entorhinal cortex entrains fast CA1 hippocampal oscillations in the anesthetized guinea pig: role of the monosynaptic component of the perforant path. Eur J Neurosci 7:1548-1557.

Christian EP, Dudek FE (1988) Electrophysiological evidence from glutamate microapplications for local excitatory circuits in the CA1 area of rat hippocampal slices. J Neurophysiol 59:110-123.

Cornell-Bell AH, Finkbeiner SM, Cooper MS, Smith SJ (1990) Glutamate induces calcium waves in culture astrocytes: long-range glial signaling. Science 247:470-473.

Czéh G, Aitken PG, Somjen GG (1993) Membrane currents in CA1 pyramidal cells during spreading depression (SD) and SD-like hypoxic depolarization. Brain Res 632:195-208.

Dani JW, Chernjavsky A, Smith SJ (1992) Neuronal activity triggers calcium waves in hippocampal astrocyte networks. Neuron 8:429-440.

Deuchars J, Thomson AM (1996) CA1 pyramid-pyramid connections in rat hippocampus in vivo: dual recordings with biocytin filling. Neuroscience 74:1009-1018.

Engel Jr J (1989) Seizures and epilepsy. Philadelphia: Davis.

Fertziger AP, Ranck Jr JB (1970) Potassium accumulation in interstitial space during epileptiform seizures. Exp Neurol 26:209-218.

Fox SE, Ranck Jr JB (1981) Electrophysiological characteristics of hippocampal complex-spike cells and theta cells. Exp Brain Res 41:299-313.

Freeman JA, Nicholson C (1975) Experimental optimization of current source-density technique for anuran cerebellum. J Neurophysiol 38:369-382.

Gloor P, Vera CL, Sperti L, Ray SN (1961) Investigation of the mechanism of epileptic discharge in the hippocampus. Epilepsia 2:42-62.

Gloveli T, Albrecht D, Heinemann U (1995) Properties of low $\mathrm{Mg}^{2+}$ induced epileptiform activity in rat hippocampal and entorhinal cortex slices during adolescence. Dev Brain Res 87:145-52.

Goddard GV, McIntyre DC, Leech CK (1969) A permanent change in brain functioning resulting from daily electrical stimulation. Exp Neurol 25:293-330.

Green JD (1964) The hippocampus. Physiol Rev 44:501-531.

Haglund MM, Schwartzkroin PA (1984) Seizure-like spreading depression in immature rabbit hippocampus in vitro. Dev Brain Res 14:51-59.

Haglund MM, Schwartzkroin PA (1990) Role of Na-K pump potassium regulation and IPSPs in seizures and spreading depression in immature rabbit hippocampal slices. J Neurophysiol 63:225-239.

Heinemann U, Lux HD, Gutnick MJ (1977) Extracellular free calcium and potassium during paroxysmal activity in cerebral cortex of the cat. Exp Brain Res 27:237-243.

Heinemann Um Eder C, Lass A (1995) Epilepsy. In: Neuroglia (Ketterman H, Ransom BR, eds), pp 936-949. New York: Oxford UP.

Herreras O, Somjen GG (1993) Propagation of spreading depression among dendrites and somata of the same cell population. Brain Res 610:276-282.

Herreras O, Largo C, Ibarz JM, Somjen GG, Martin del Rio R (1994) Role of neuronal synchronizing mechanisms in the propagation of spreading depression in the in vivo hippocampus. J Neurosci 14:7087-7098.

Holsheimer J (1987) Electrical conductivity of the hippocampal CA1 layers and application to current source density analysis. Exp Brain Res 67:402-410.

Ikeda A, Terada K, Mikuni N, Burgess RC, Comair Y, Taki W, Hamano T, Kimura J, Lüders HO, Shibasaki H (1996) Subdural recording of ictal DC shifts in neocortical seizures in humans. Epilepsia 37:662-674.

Jefferys JGR (1981) Influence of electric fields on the excitability of granule cells in guinea pig hippocampal slices. J Physiol (Lond) 319:143-152.

Jefferys JGR, Haas HL (1982) Synchronized bursting of CA1 hippocampal pyramidal cells in the absence of synaptic transmission. Nature 300:448-450.

Katsumaru H, Kosaka T, Heizman CW, Hama K (1988) Gap junctions on GABAergic neurons containing the calcium-binding protein parvalbumin in the rat hippocampus (CA1 regions). Exp Brain Res 72:363-370.

Korn SJ, Giacchino JL, Chamberlin NL, Dingledine R (1987) Epileptiform burst activity induced by potassium in the hippocampus and its regulation by GABA-mediated inhibition. J Neurophysiol 57:325-340.

Klishin A, Tsintsadze T, Lozovaya N, Krishtal O (1995) Latent $N$-methyl$\mathrm{D}$-aspartate receptors in the recurrent excitatory pathway between hippocampal CA1 pyramidal neurons: $\mathrm{Ca}^{2+}$-dependent activation by blocking A1 adenosine receptors. Proc Natl Acad Sci USA 92:12431-12435.

Kuffler SW, Nicholls JG (1966) Neuroglial cells: physiological properties and potassium mediated effect of neuronal activity on the glial membrane potential. Proc R Soc Lond [Biol] 168:1-21.

Leao AAP (1944) Spreading depression of activity in the cerebral cortex. J Neurophysiol 7:359-390.

Leao AAP (1972) Spreading depression. In: Experimental models of epilepsy: a manual for the laboratory worker (Purpura DP, Penry JK, Tower DB, Woodbury DM, Walter RD, eds), pp 174-196. New York: Raven.

Leung LS (1979) Potentials evoked by the alvear tract in hippocampal CA1 of rats. II. Spatial field analysis. J Neurophysiol 42:1571-1589.

Leung LS (1987) Hippocampal electrical activity following local tetanization. I. Afterdischarges. Brain Res 419:173-187.

Leung LS (1982) Nonlinear feedback model of neuronal populations in hippocampal CA1 region. J Neurophysiol 47:845-868.

Li X-G, Somogyi P, Ylinen A, Buzsáki G (1994) The hippocampal CA3 network: an in vivo intracellular labeling study. J Comp Neurol 339:181-208.

Liberson WT, Cadilhac J (1953) Further observations on DC potentials during electrically induced seizure discharge activity in guinea pig. Electroencephalogr Clin Neurophysiol 5:320-324.

Lothman EW, Williamson JM (1993) Rapid kindling with recurrent hippocampal seizures. Epilepsy Res 14:209-220.

MacVicar BA (1984) Voltage-dependent calcium channels in glial cells. Science 226:1345-1347.

Martins-Ferreira H, Ribeiro LJ (1995) Biphasic effects of gap junctional uncoupling agents on the propagation of retinal spreading depression. Brazil J Med Biol Res 28:991-994.

McNamara JO (1994) Cellular and molecular basis of epilepsy. J Neurosci 14:3413-3425.

Mitzdorf U (1985) Current source-density method and application in cat cerebral cortex: investigation of evoked potentials and EEG phenomena. Physiol Rev 65:37-100.

Mody I (1993) The molecular basis of kindling. Brain Pathol 3:395-403.

Nedergaard M (1994) Direct signaling from astrocytes to neurons in cultures of mammalian brain cells. Science 263:1768-1771.

Nedergaard M, Cooper AJ, Goldman SA (1995) Gap junctions are required for the propagation of spreading depression. $J$ Neurobiol 28:433-44.

Parpura V, Basarsky TA, Liu F, Jeftinija K, Jeftinija S, Haydon PG 
(1994) Glutamate-mediated astrocyte-neuron signalling. Nature 369:744-747.

Pedley TA, Fisher RX, Futamachi KJ, Prince DA (1976) Regulation of extracellular potassium concentration in epileptogenesis. Fed Proc 35:1254-1259.

Penfield W, Jasper H (1954) Epilepsy and the functional anatomy of the human brain. Boston: Little \& Brown.

Penttonen M, Bragin A, Sik A, Buzsáki G (1995) Dye coupling of neurons in the hippocampus implies a role for gap junctions in epilepsy. Soc Neurosci Abstr 21:1971.

Perez-Velazquez JL, Valiante TA, Carlen PL (1994) Modulation of gap junctional mechanisms during calcium-free induced field burst activity: a possible role for electrotonic coupling in epileptogenesis. J Neurosci 14:4308-4317.

Psarropoulou C, Avoli M (1993) 4-Aminopyridine-induced spreading depression episodes in immature hippocampus: developmental and pharmacological studies. Neuroscience 55:57-68.

Racine RJ (1972) Modification of seizure activity by electrical stimulation. I. Afterdischarge threshold. Electroencephal Clin Neurophysiol 32:281-294.

Stringer JL, Williamson JM, Lothman EW (1991) Maximal dentate activation is produced by amygdala stimulation in unanesthetized rats. Brain Res 542:336-342.

Quandt FN, MacVicar BA (1986) Calcium activated potassium channels in cultured astrocytes. Neuroscience 19:29-41.

Radpour S, Thomson AM (1991) Coactivation of local circuit NMDA receptor mediated epsps induces lasting enhancement of minimal schaffer collateral EPSPs in slices of rat hipocampus. Eur J Neurosci 3:602-613.

Ransom BR (1995) Gap junctions. In: Neuroglia (Ketterman H, Ransom BR, eds). New York: Oxford UP.

Schweitzer JS, Patrylo PR, Dudek FE (1992) Prolonged field bursts in the dentate gyrus: dependence on low calcium, high potassium, and nonsynaptic mechanisms. J Neurophysiol 68:2016-2025.

Sik A, Penttonen M, Ylinen A, Buzsáki G (1995) Hippocampal CA1 interneurons: an in vivo intacellular labeling study. J Neurosci 15:6651-6665.

Sloviter RS (1983) "Epileptic" brain damage in rats induced by sustained electrical stimulation of the perforant path. I. Acute electrophysiological and light microscopic studies. Brain Res Bull 10:675-697.
Soltész I, Dechenes M (1993) Low and high frequency membrane potential oscillation during $\theta$ activity in CA1 and CA3 pyramidal neurons of the rat hippocampus under ketamine-xylazine anesthesia. J Neurophysiol 70:97-116.

Somjen GG, Giacchino JL (1985) Potassium and calcium concentrations in interstitial fluid of hippocampal formation during paroxismal discharges. J Neurophysiol 53:1098-1108.

Somjen GG, Aitken PG, Giacchino JL, McNamara JO (1985) Sustained potential shifts and paroxysmal discharges in hippocampal formation. J Neurophysiol 53:1079-1097.

Stumpf C (1965) Drug action on the electrical activity of the hippocampus. Int Rev Neurobiol 8:77-138.

Sypert GW, Ward AA (1971) Unidentified neuroglia potentials during propagated seizures in the neocortex. Exp Neurol 33:239-255.

Takato M, Goldring S (1979) Intracellular marking with lucifer yellow $\mathrm{CH}$ and horseradish peroxidase of cells electrophysiologically characterized as glial in the cerebral cortex of the cat. J Comp Neurol 186:173-188.

Taylor CP, Dudek FE (1982) Synchronous neural afterdischarges in rat hippocampal slices without active chemical synapses. Science 218:810-812.

Traynelis SF, Dingledine R (1988) Potassium-induced spontaneous electrographic seizures in the rat hippocampal slice. J Neurophysiol 59:259-276.

Wadman WJ, Juta AJA, Kamphuis W, Somjen GG (1992) Current source density analysis of sustained potential shifts associated with electrographic seizures and with spreading depression in rat hippocampus. Brain Res 570:85-91.

Wang X-J, Buzsáki G (1996) Gamma oscillation by synaptic inhibition in an interneuronal network model. J Neurosci 16:6402-6413.

Whittington MA, Traub RD, Jefferys JGR (1995) Metabotropic receptor activation drive synchronized $40 \mathrm{~Hz}$ oscillations in networks of inhibitory interneurons. Nature 373:612-615.

Ylinen A, Bragin A, Nádasdy Z, Jandó G, Szabó I, Sik A, Buzsáki G (1995) Sharp wave associated high frequency oscillation $(200 \mathrm{~Hz})$ in the intact hippocampus: network and intracellular mechanisms. J Neurosci 14:30-46. 